\title{
Signaling in International Environmental Agreements: The Case of Early and Delayed Action
}

\section{Potsdam Institute for Climate Impact Research (PIK)}

\author{
Michael Jakob ${ }^{1}$, Kai Lessmann
}

March 2011

\section{Abstract}

15 This paper presents a stylized IEA game with two asymmetric regions differing in their benefits from environmental quality. If side payments are allowed, cooperation can increase the payoffs accruing to both regions. However, cooperation can be impeded by asymmetric information about the regions' types and only become feasible once a region has credibly revealed its type. We show how in a two-stage game as well as in continuous time early (delayed) action can act as a signal to reveal private information on high (low) benefits. The cooperative solution with asymmetric information is Pareto-dominated by the outcome with perfect information.

\section{Keywords: International Environmental Agreements, Climate}

\footnotetext{
${ }^{1}$ Corresponding author: jakob@pik-potsdam.de, Tel. ++49-331 288 2650, P.O.Box 601203, 14412 Potsdam, Germany, www.pik-potsdam.de
} 


\section{Introduction}

Several recent studies based on integrated assessment modeling find that early action can significantly reduce the costs of mitigating climate chance (Edmonds et al. 2008; van Vliet et al. 2009; Clarke et al. 2009) $)^{2}$. Furthermore, it has been pointed out that delaying the inception of a global climate agreement can influence strategic behavior, as countries face incentives to lower their investments in abatement technologies to improve their future bargaining position (Harstad 2009; Beccherle and Tirole 2010). In spite of these arguments in favor of early action, negotiations on a climate

10 agreement to replace the Kyoto protocol after its expiry in 2012 suffered a serious setback at COP-15 in Copenhagen. Nonetheless, the EU has adopted the target to unilaterally reduce GHG emissions by $20 \%$ to $30 \%$ below 1990 levels by 2020 . It has been argued that action by only a small number of countries but inaction by the large majority can be explained by free-riding behavior, which allows for only a low number of active participants in international environmental agreements (e.g. Cararro and Siniscalco 1993; Barrett 1994). However, several recent contributions have identified schemes that can bring the level of climate protection close to the global optimum by matching regions that exhibit the highest willingness to pay for abatement of GHG emissions with regions that feature the lowest mitigation costs (Carbone et al. 2009; Weikard et al. 2006; Carraro et al. 2006).

Yet, despite the possibility of employing optimal transfer schemes in practice, currently there seems little prospect for a global agreement to emerge in the near future. This paper argues that uncertainty arising from asymmetric information can provide a plausible explanation of this outcome. It demonstrates that if mutually desirable cooperation is impeded by imperfect information, early as well as delayed action can be employed as signals that credibly reveal private information and lay the foundation for future cooperation.

In a setting in which parameters relevant for policy formulation (such as citizens' concern for the environment and future generations, which affect the benefits of

\footnotetext{
${ }^{2}$ For instance, Jakob et al. (2011) estimate that postponing a global agreement to 2020 raises global mitigation costs by at least about half and a delay to 2030 renders stabilizing atmospheric GHG concentrations at $450 \mathrm{ppm} \mathrm{CO}_{2}$-only infeasible
} 
climate change mitigation) cannot be verified by outsiders, informational asymmetries can crucially shape strategic interactions. While the insights provided by the economics of information have revolutionized numerous branches of economics (Stiglitz 2000), the issue of informational asymmetries does not feature prominently 5 in the context of international environmental agreements. The large majority of contributions in this area focus on optimal contracts designed to ensure that truthful revelation of one's type by means of self-selection is a dominant strategy. Matsueda (2004) shows that if a pollutee has imperfect information with regard to a polluter's environmental preference, incentive conflicts can arise that make it impossible to 10 achieve an agreement to mitigate trans-boundary pollution. Batabyal (2000) demonstrates that if an international environmental agreement is unable to observe firms' private information, it can be hampered by collusion between national governments and firms. Several optimal second-best contracts have been proposed to deal with problems related to asymmetric information. For instance, Caparrós et al.

15 (2004) as well as Helm and Wirl (2009) identify optimal transfer payment schemes subject to bargaining in North-South climate negotiations in the face of private information. Laffont and Martimont (2005) focus on pricing strategies in games with multiple hierarchies in which a principal pays an agent for the provision of a transnational public good, and Mason (2010) proposes a solution to reduce $\mathrm{CO}_{2}$

20 emissions from deforestation that minimizes its budgetary impact by means of a menu of two-part contracts (consisting of lump-sum plus variable payments) from which forest owners can choose.

By contrast, the role of signaling in international environmental agreements has, to 25 our knowledge, received only limited attention: Rose and Spiegel (2009) present empirical evidence that countries might use their membership in international environmental agreements as a device to signal a low rate of time preference in order to obtain credit at preferential rates from the global capital market. The models by Harstad and Eskeland (2010), in which firms over-purchase emission permits to signal

30 high mitigation costs to the regulator (and receive higher allocation of free permits in the next period), and Denicolò (2008), in which firms engage in environmental overcompliance in order to induce stricter regulation and raise their rivals' costs by more than their own could very likely also be applied to the interaction between national governments and an IEA's supra-national authority. The main difference between 
these contributions and our approach is that in the former, signaling is used within an already existing environmental agreement, while we examine how signaling can contribute to the conclusion of such an agreement. Finally, Brandt (2004) develops a model in which abatement costs are uncertain and positively correlated across countries. A country that becomes privately informed can then engage in unilateral early action to reveal a low overall level of abatement costs. Brandt's model significantly differs from the model presented in this paper: in the former early action is desirable to reveal information regarding one's own mitigation costs to other countries (and trigger additional abatement if these costs are low), while in our model

10 the motivation to engage in early action or not is to reveal certain private information about the magnitude of a country's benefits.

This research article presents a stylized model in which asymmetric information can preclude the successful conclusion of an international environmental agreement that 15 would be stable under perfect information. We propose a game structure (in a twostage game as well as in continuous time) appropriate to demonstrate how unilateral early (delayed) action can be employed to credibly signal high (low) benefits from mitigating climate change. We also derive conditions necessary for the existence of a separating equilibrium - in which truthful revelation of private information constitutes 20 a dominant strategy - and show that in terms of welfare the cooperative outcome under asymmetric information is strictly inferior to the outcome obtained with perfect information.

This paper proceeds as follows: Section 2 presents a simple model of provision of a 25 global public good with complete information, Section 3 shows how asymmetric information can inhibit cooperation, Section 4 discusses in which way the timing of action can be employed as a signal to reveal private information, and Section 5 extends the model to continuous time. Section 6 discusses the results in the light of the current policy debate and draws conclusions for further research. 


\section{Cooperation in International Environmental Agreements with Complete Information}

In order to highlight the economic mechanisms through which asymmetric information enters a game of global public good provision, we adopt a simple model which divides the world in two regions, 'North' and 'South'3 . Both regions can provide the global public good entailing costs $c_{N}$ and $c_{S}$ as well as benefits $b_{N}$ and $b_{S}{ }^{4}$. The case of interest is the one in which each region's costs are higher than its individual benefits (i.e. $c_{N}>b_{N}$ and $c_{S}>b_{S}$ ) but in which mutual cooperation can

10 bring about a Pareto-superior outcome (i.e. $b_{N}+b_{S}>c_{S}$ or $b_{N}+b_{S}>c_{N}$, respectively). As is common in public good provision, this setting causes underprovision of the good. However, in this situation side-payments can be used to alter the game's pay-off structure such that cooperation becomes desirable for both regions.

15 Let both players simultaneously choose their (pure) strategies in a one-shot game from the set 'cooperation' or 'non-cooperation'. In this context, cooperation for the North means effecting a transfer payment $T$ to the South, while for the South cooperation is understood as providing the public good. If both players choose not to cooperate, they receive zero payoffs. If any player chooses non-cooperation but the

20 other cooperates (let's call this behavior 'cheating') either (a) South supplies the public good without receiving the promised payment, or (b) North pays the transfer without South engaging in the provision of the public good. Assume that a system of measurement, reporting, and verification (MRV), whose quality is inversely related to the parameter $\gamma(\gamma<1)$, exists. For instance, $\gamma$ can be understood as the probability that

25 cheating can occur without being noticed. By means of MRV cheating by any player can be detected before the end of the game. In this case, both players continue to behave non-cooperatively until the end of the game and the costs and benefits that

\footnotetext{
${ }^{3}$ Formally this model is similar to Caparrós et al. (2004), where informational advantages can improve a region's bargaining position. In our paper, however, it is desirable to truthfully reveal private information which can only be achieved through a signal, leaving both parties worse off than in the case with complete information.

${ }^{4}$ This particular pay-off structure corresponds to a model with linear cost and benefit functions (as e.g. in Barrett 1994 or Finus and Rübbelke 2008) that results in a binary choice whether abatement is performed or not (i.e. a 'bang-bang' solution)
} 
occur are only a fraction $\gamma$ of what they would be if cooperation were upheld over the entire game ${ }^{5}$ (Figure 1).

$<<$ Figure 1 about here $>>$

5

Whether the cooperative outcome constitutes a Nash-equilibrium depends on the relative payoffs associated with cooperation and cheating: if North chooses to cooperate, South's best response is cooperation if $b_{S}-c_{S}+T>\gamma T$, i.e. if North offers a transfer exceeding the minimum transfer $T^{\min }$

10

$T>\frac{c_{S}-b_{S}}{(1-\gamma)} \equiv T^{\min }$

Likewise, if South cooperates, North prefers cooperation over non-cooperation if $b_{N}-T>\gamma b_{N}$, i.e. if the transfers due are not too expensive.

15

$T<(1-\gamma) b_{N} \equiv T^{\max }$

Let us at as a shorthand for later use introduce a (exogenously given) surplus sharing scheme characterized by a parameter $\alpha(0<\alpha<1)$ to determine which value of the transfer between the minimal amount that South is willing to accept and the maximum value North is prepared to provide will actually be realized, provided that cooperation is feasible (i.e. Eq. 1 and 2 both hold):

$T=\alpha T^{\min }+(1-\alpha) T^{\max }$

25

Combining the expressions for $T^{\min }$ and $T^{\max }$ yields the condition for the existence of transfers that sustain a cooperative equilibrium:

$b_{N}>\frac{c_{S}-b_{S}}{(1-\gamma)^{2}}$.

\footnotetext{
${ }^{5}$ Hence, $\gamma$ is a conversion factor between those costs/benefits that occur over the entire game and those that are terminated after non-cooperation is detected
} 
The above inequality is satisfied for (i) low net costs $c_{S}-b_{S}$ of providing the public good in the South, (ii) high benefits $b_{N}$ in the North, and (iii) a low value of $\gamma$, which mitigates incentives to free-ride on the other player's cooperative behavior. If condition 4 is fulfilled, the game is no longer a Prisoners' Dilemma (in which noncooperation is a dominant strategy for each player) but becomes a game of coordination (in which mutual cooperation constitutes a second Nash-equilibrium that Pareto-dominates the non-cooperative outcome; see, for example, Schelling 1960) ${ }^{6}$. For the purpose of this paper, we posit that whenever mutual cooperation constitutes a

10 Nash-equilibrium, the cooperative strategies are the "obvious way" to play the game and hence we will consider cooperation the "solution" of the coordination game. This in fact does not require any kind of commitment device; it is sufficient that the players can communicate without incurring costs - once they agree to coordinate their actions, no player has an incentive to unilaterally switch to non-cooperation.

\section{Asymmetric Information as an Obstacle to Cooperation}

Having discussed the conditions for cooperation with perfect information, we now turn to the case with asymmetric information about the other country's benefits. Own benefits are known to each region with certainty, but there can be uncertainty with regard to the benefits of the other region. ${ }^{7}$ Asymmetric information on the country level are commonly assumed in the respective literature (e.g. Batabyal, 2000; Matsueda, 2004; Caparrós et al., 2004; Rose and Spiegel, 2009). This assumption is 25 far from trivial, as it implies that the valuations and decision procedures of one country's government are only known with uncertainty to others. As this paper focuses on the question of how asymmetric information can impede cooperation and how signaling can be employed to achieve Pareto-improvements, we take asymmetric

\footnotetext{
${ }^{6}$ We do not consider the situation of a Chicken game in our analysis (see e.g. Pittel and Rübbelke 2008)

${ }^{7}$ Benefits arguably constitute the most relevant source of asymmetric information, as they represent not only physical and economic damages, but also a willingness to pay for climate change mitigation. This also depends on normative parameters, such as intergenerational justice and concern for the environment (Gardiner, 2004)
} 
information as a given. Yet, the precise mechanism how these informational can asymmetries arise is an issue that deserves further attention in future research.

To keep the analysis tractable, we limit the discussion to settings in which the benefits

5 of one region are known with certainty to both regions, while the other region's benefits can take on one of two possible values, either high or low. A region whose true benefits are high is referred to as being of the h-type, conversely l-type regions have low benefits. From the perspective of South, if the type of North is unknown, it can take on either of the two discrete values $b_{N}^{h}$ or $b_{N}^{l}$ with probabilities $p_{N}$ and

$101-p_{N}$, respectively. ${ }^{8}$ Likewise, North believes South to be an h-type with benefits $b_{S}^{h}$ with a probability of $p_{S}$, or an 1-type with benefits $b_{S}^{l}$ with probability $\left(1-p_{S}\right)$ if her true benefits are uncertain.

$<<$ Figure 2 about here $>>$

15

Figure 2 formalizes the case in which North's true benefits are unknown to South as a one-stage game in extended form. In stage 0, Nature moves, pinning down whether North is an h-type or l-type. Then, North and South move simultaneously in stage 1. When benefits of North are uncertain to South, the existence condition for a cooperative solution from the previous section (Eq. 4) translates into a threshold where cooperation (non-cooperation) is North's best response to cooperation by South if $b_{N}$ is above (below) the threshold. Otherwise, the realization of the (uncertain) $b_{N}$ does not matter for North's choice of strategy and - using the expected instead of the certain values of $b_{N}$ - the problem becomes formally equivalent to the one with full 25 information uncertainty discussed in Section 2. Suppose that whether North's benefits are high or low makes a difference for his optimal strategy, i.e.

$b_{N}^{l}<\frac{c_{S}-b_{S}}{(1-\gamma)^{2}}<b_{N}^{h}$

\footnotetext{
${ }^{8}$ While only the players know their true type, we assume that all probabilities are common knowledge
} 
Notice that the threshold depends on the benefit parameter of the North and therefore on its type. Under these conditions, what is the impact of uncertainty on the strategy of South?

5 Lemma 1: If $b_{N}$ is uncertain and North's action depends on his type (i.e. if the condition of Eq. (4') holds), the cooperative outcome is only obtained if North is an htype and South expects with a sufficiently high probability that North is an h-type.

Proof: From the previous section and the definition of high and low benefits we know 10 the equilibria of the second stage: if North expects South to cooperate, he too cooperates if he is an h-type, but plays non-cooperatively if he is an l-type. If, however, North expects non-cooperation by South, he chooses non-cooperation regardless of his type. $p_{N}$ being public knowledge allows North to anticipate South's action. He expects cooperation by South (and, if he is an h-type, North cooperates, 15 too) if the latter's expected payoff from cooperation exceeds her expected payoff from non-cooperation ${ }^{9}$. Hence, South's expected payoff from cooperation is:

$\pi_{S, c}^{e}=p_{N}\left(b_{S}-c_{S}+T\right)+\left(1-p_{N}\right) \gamma\left(b_{S}-c_{S}\right)$

20 while the expected payoff of playing non-cooperatively is

$$
\pi_{S, n c}^{e}=p_{N} \gamma T
$$

South chooses the (pure) strategy that yields the highest expected payoff. Solving for 25 $p_{N}$ then yields the following condition for cooperation (i.e. $\pi_{S, c}^{e}>\pi_{S, n c}^{e}$ ):

$$
p_{N}>\frac{\gamma\left(c_{S}-b_{S}\right)}{(1-\gamma)\left(b_{S}-c_{S}+T\right)}
$$

\footnotetext{
${ }^{9}$ That is, mutual cooperation constitutes a Nash-equilibrium that is Pareto-superior from the noncooperative outcome.
} 
Hence, South's expected benefit only warrants cooperation if the probability of North being an h-type is sufficiently high. This means that South needs to be adequately optimistic that playing cooperatively will be met by cooperation by North (and hence pay off). However, if North is an h-type but South assigns too low a probability to this state, no cooperation (which would be beneficial for both regions) can occur, as South has no means of verifying North's true type.

Now consider the effect of incomplete information from the perspective of North: if North was inclined to cooperate, he would offer a transfer payment $T$. For low or high benefits in South, the volumes of the transfer payment are high or low, respectively (Eq. 1-3 $)^{10}$. This leaves North with three choices: either offering transfers $T^{-}$or $T^{+}$corresponding to South being an h- or 1-type, respectively $\left(T^{-}<T^{+}\right)$, or no transfers (i.e. playing non-cooperatively) $(n)$. Figure 3 shows the game structure and payoffs for this situation. If North agrees to pay the (higher) transfer $T^{+}$, South's 15 incentive compatibility condition Eq.(1) is fulfilled for $\mathrm{h}$ - as well as 1-types and cooperation occurs, regardless of South's true type. If, on the other hand, $T^{-}$(the transfer that corresponds to an h-type) is sufficient to induce cooperation even if South is an 1-type (i.e. if $T^{-}>\frac{c_{S}-b_{S}^{l}}{(1-\gamma)}$ ), North obviously has no incentive to offer a higher transfer. In this case, the cooperative equilibrium is achieved with North 20 offering $T^{-}$, provided that North's benefits are sufficiently high such that mutual cooperation yields a higher payoff than cheating (cf. Eq. 4). Otherwise, in the case in which North never cooperates (i.e. Eq. 4 holds for neither realization of $b_{N}$ ), South anticipates this strategy and the game trivially results in the non-cooperative equilibrium. The case of interest is hence the one in which South's reaction to North's 25 transfer offer depends on her type. Restating Eq.(1), this can be expressed as:

$$
\frac{c_{S}-b_{S}^{l}}{(1-\gamma)}>T^{-}>\frac{c_{S}-b_{S}^{h}}{(1-\gamma)}
$$

\footnotetext{
${ }^{10}$ That is, the transfer North has to offer to make cooperation worthwhile is the higher the lower South's benefits $b_{\mathrm{S}}$.
} 
Again, if Eq.(1') does not hold, South's reaction to North's transfer offer does not depend on its type and the game can be expressed in the simple form discussed in Section 2.

Lemma 2: If $b_{S}$ is uncertain and South's reaction to the transfer offered by North depends on her type (i.e. Eq.(1') holds), the cooperative outcome is only obtained if (a) either South is an h-type, or if (b) North expects with a sufficiently high 10 probability that South is an l-type.

Proof: We only have to consider constellations in which North prefers mutual cooperation over free-riding, i.e. $b_{N}^{h}$ is high enough (cf. Eq. 4). With perfect information, North would then agree to pay a transfer $T$ that is a function of South's

15 benefits $b_{S}$. Under incomplete information, however, this transfer depends on South's type since $T$ is a function of South's benefits ${ }^{11}$. South then has an incentive to pass as an l-type in order to extract a higher transfer payment, even if she is an h-type. North in turn offers the transfer payment which results in the highest expected payoff. For the transfer corresponding to South being an l-type (i.e. $T^{+}$), cooperation always occurs, yielding the certain payoff:

$\pi_{N, c}^{+}=b_{N}-T^{+}$

Given the conditions stated in the Lemma, the expected payoff for offering $T^{-}$is 25 given by:

$$
\pi_{N, c}^{-, e}=p_{S}\left(b_{N}-T^{-}\right)+\left(1-p_{S}\right)\left(-\gamma T^{-}\right),
$$

\footnotetext{
${ }^{11}$ Please note that a transfer is always offered by North, as the (higher) transfer $T^{+}$guarantees cooperation, which is Pareto-superior to free-riding for the cases considered here
} 
That is, North derives a net payoff of $b_{N}-T^{-}$if South is an h-type (in which case mutual cooperation occurs), but $-\gamma T^{-}$if South is an l-type (and hence does not cooperate). North then opts for $T^{+}$if $\pi_{N, c}^{+}>\pi_{N, c}^{-, e}$, which is satisfied if

$5 \quad p_{S}<\frac{b_{N}-T^{+}+\gamma T^{-}}{b_{N}-(1-\gamma) T^{-}}$.

Assuming that Eq.(1') holds, a transfer $T^{-}$is sufficient to ensure mutual cooperation if South is an h-type; for an 1-type, however, non-cooperation would yield a higher payoff $^{12}$. Hence, if South is an 1-type but North assigns a sufficiently high probability $10 p_{S}$ to her being an h-type, the game results in a situation in which North is willing to cooperate but only offers $T^{-}$, such that South defects (even though cooperation with the higher transfer payment $T^{+}$would constitute a Pareto-superior outcome).

In summary, cooperation can be impeded by uncertainty if the actual realization of the uncertain parameters would mandate cooperation but the player being confronted with uncertainty expects that such a realization is too unlikely to mandate cooperation. For a brief illustration, we use a simple numerical example with plausible parameter values, assuming that the net present value of the future damages from unmitigated climate change range from 4\% to 8\% of global GDP (Stern 2007 reports estimates between $5 \%$ and $20 \%$ ), distributed at a ratio of 3:1 between North and South and a surplus-sharing parameter of $\alpha=2 / 3$ (Table 1). Let us assume that North's true benefits are $b_{N}^{h}$, and South's are $b_{S}^{l}$. With perfect information, the minimum transfer for which South is prepared to cooperate is $T_{\min }=\frac{c_{S}-b_{S}}{(1-\gamma)}=2.5 \%$, and the maximum North is ready to pay amounts to $T_{\max }=(1-\gamma) b_{N}=4.5 \%$, such that the cooperative equilibrium is achieved with a transfer payment of:

$$
T=\alpha T_{\min }+(1-\alpha) T_{\max }=\frac{2}{3} \cdot 2.5 \%+\frac{1}{3} \cdot 4.5 \% \approx 3.27 \%
$$

\footnotetext{
${ }^{12}$ Due to the game's information structure, South is able to anticipate North's action without uncertainty
} 
With asymmetric information, however, for South the expected pay-off from cooperation only exceeds the payoff from non-cooperation if she expects North to be a high-benefit type with a probability of at least:

5

$p_{N}>\frac{\gamma\left(c_{S}-b_{S}\right)}{(1-\gamma)\left(b_{S}-c_{S}+T\right)}=\frac{0.2 \cdot 2 \%}{0.8 \cdot(3.27 \%-2 \%)} \approx 0.39$

Likewise, for North it is only worthwhile to offer the transfer $T^{+}$if it is sufficiently certain that South is a low-benefit type:

10

$$
p_{S}<\frac{b_{N}-T^{+}+\gamma T^{-}}{b_{N}-(1-\gamma) T^{+}}=\frac{6 \%-3.27 \%+0.2 \cdot 2.43 \%}{6 \%-0.8 \cdot 2.43 \%} \approx 0.79
$$

In this case $T^{+}$is indeed necessary to bring about cooperation. Otherwise, North offers the lower transfer $T^{-}$, for which South's best response is non-cooperation.

15

$$
<<\text { Table } 1 \text { about here }>>
$$

\section{Signaling as a Mechanism to Overcome the Information Problem}

The preceding section has demonstrated that in certain settings where cooperation would be mutually advantageous (and an equilibrium outcome under perfect information) asymmetric information can thwart cooperation. As discussed in Lemmas 1 and 2, this outcome prevails if region A's best response to cooperation by B depends on A's type, but B is too pessimistic that A is of the cooperative type. This means that either (i) North is of the high-benefit type, but South thinks that his benefits are likely to be low, or (ii) South is a low-benefit type, but North assigns a high probability to her having high benefits. In both constellations, the player with private information would benefit from truthfully revealing his actual type. In this 
section we (a) demonstrate that early or delayed action can act as signals ${ }^{13}$ of a player's true type, and (b) identify conditions under which separating equilibria (in which the truthful revelation of one's type is a dominant strategy) are feasible.

5 For this reason, we extend the game by adding a preliminary stage, in which one player's type is known with certainty, while the other one's is uncertain. Benefits and expectations are as described above, such that cooperation would arise with perfect information but cannot occur with incomplete information in this preliminary stage. However, a player's action in the preliminary stage can reveal his type and make 10 cooperation in the second stage possible. This signal - below we show that for North it consists of early unilateral abatement, and of refusing a transfer payment and delaying abatement for South - has to be incentive compatible, such that choosing the action that yields the highest payoff reveals a player's true type. In this case the outcome is characterized as a 'separating equilibrium'. Otherwise a 'pooling 15 equilibrium', in which a player's type cannot be determined from their action in the preliminary stage, results and signaling is not feasible. Therefore, if North has credibly revealed in the first stage that he is of high-benefit type, South chooses to cooperate in the second stage; likewise, if South has credibly established that she is an 1-type in the first stage, North is prepared to provide the appropriate transfer and the cooperative outcome is obtained in the second stage. Yet, as cooperation from the first stage on would have yielded a Pareto-superior result, the signaling outcome is not optimal from a social welfare perspective ${ }^{14}$.

To be able to compare costs between periods, we further need to introduce a conversion factor $\delta_{N, S}$ to take into account the effects of discounting the future and the possibility that the game's two stages are of different length (in this case costs and benefits should be regarded as flow variables and $\delta_{N, S}$ can have values lower or higher than one).

\footnotetext{
${ }^{13}$ In this context a signal that credibly conveys private information not directly observable to the counterparty is an action that is worthwhile pursuing for one type of player but not for the other one (Spence, 1973).

${ }_{14}$ That is, acquiring a credible signal entails social costs (that would be avoided under perfect information) and the first best outcome cannot be attained.
} 
Proposition 1: If cooperation is impeded by asymmetric information, early action by North can be a credible signal of high benefits

Proof: The payoffs for both players are shown in Figure 4. South acts cooperatively in the second stage of the sub-game if North has credibly established that it is of the high-benefit type. Taking early action, North incurs negative net benefits $b_{N}-c_{N}$ in the first period, which are rewarded by positive ones corresponding to a present value of $\delta_{N}\left(b_{N}-T\right)$ if cooperation occurs, but $\delta_{N} \gamma b_{N}$ if he cheats in the second period, freeriding on South's mitigation effort. A separating equilibrium then exists if for an htype the benefits of cooperation in the second stage exceed the costs borne in the first stage, but for an 1-type the rewards of free-riding do not.

First, the incentive compatibility condition ensuring that it does not pay off for North to pretend to be an h-type by taking early action if in reality he is an 1-type reads:

15

$$
\left(b_{N}^{l}-c_{N}\right)+\delta_{N} \gamma b_{N}^{l}<0,
$$

see nodes \#1 and \#2 in Figure 4.

20 That is, the rewards of free-riding in the second stage are not sufficient to compensate for the costs of sending the signal in the first stage ${ }^{15}$. This condition of Eq.(11) can be rewritten as:

$b_{N}^{l}<\frac{c_{N}}{1+\gamma \delta_{N}}$

Taking early action in order to be able to cheat in the second stage becomes less attractive for a Northern 1-type, (a) the lower $b_{N}^{l}$ (i.e. the benefits of enjoying the public good in the first period and of free-riding in the second one), (b) the larger $c_{N}$

\footnotetext{
${ }^{15}$ Without early action by North, mutual non-cooperation results in both stages of the game, yielding a payoff of zero.
} 
(i.e. the costs of sending the signal in the first stage), and (c) the lower $\gamma$ and $\delta_{N}$ (which scale the expected net-benefits from free-riding).

Second, if North is an h-type, early action is only worthwhile if the sum of his net

5 costs in the first stage and the benefits of cooperation in the second stage exceed the pay-off from non-cooperation during both periods, i.e.:

$\left(b_{N}^{h}-c_{N}\right)+\delta_{N}\left(b_{N}^{h}-T\right)>0$,

10 see nodes \#3 and \#4 in Figure 4.

Eq.(12) is equivalent to

$b_{N}^{h}>\frac{c_{N}+\delta_{N} T}{1+\delta_{N}}$.

15

A Northern h-type is thus more likely to successfully signal his type if (a) $b_{N}^{h}$ is large (which results in lower net costs in the first stage as well as higher net benefits in the second one), if (b) $c_{N}$ and $T$ are low (lower costs to provide the signal in the first stage and to pay South for its provision of the public good in the second one), and if 20 (c) $\delta_{N}$ is large (higher valuation of the benefits occurring in the second stage compared to first stage costs).

Hence, a separating equilibrium for North exists if both conditions (11) and (12) are fulfilled, i.e. if $b_{N}^{l}$ is sufficiently small and $b_{N}^{h}$ sufficiently high. If one of them is 25 violated, it either pays off for l-types to take early action but cheat in the second period, or it is not worthwhile for h-types to incur the extra costs of the signal in the first stage. In this case a pooling equilibrium, in which types cannot be distinguished by their first stage behavior (i.e both would choose identical actions) results. For instance, using the parameters employed in the numeric example (cf. Table 1), and 30 assuming that $b_{S}=b_{S}^{h}=2 \%$ and $c_{N}=8 \%$, it is easy to verify that Eq.(11) is fulfilled 
if $\delta_{N}<8.33$, and (Eq. 12) if $\delta_{N}>0.73$, and a separating equilibrium exists if $\delta_{N}$ falls in the range $0.73<\delta_{N}<8.33$.

5 Proposition 2: If cooperation is impeded by asymmetric information, delay of action by South can be a credible signal of low benefits

Proof: As we have shown in Lemma 2, cooperation can be impeded by asymmetric information if South is an 1-type who only cooperates if offered the $\operatorname{transfer} T^{+}$(but 10 not if offered $T^{-}$) but North assigns a high probability to South being an h-type. With this false expectation, North offers the transfer $T^{-}$in the first period. Using backward induction (Figure 5), we see that if South can successfully use non-cooperation in the first period to signal that she is a low-benefit type, North offers the transfer $T^{+}$in the second period and a Pareto-improvement results from cooperation. Otherwise (i.e. if

15 South cooperates in the first period), North's second period offer will remain $T^{-}$.

The second condition for a separating equilibrium is that low-benefit types must prefer playing non-cooperatively in the first period and cooperate in the second one with the transfer $T^{+}$over cooperation in both periods with the lower $\operatorname{transfer} T^{-}$:

20

$\left(b_{S}^{l}-c_{S}+T^{-}\right)+\delta_{S}\left(b_{S}^{l}-c_{S}+T^{-}\right)<\gamma T^{-}+\delta_{S}\left(b_{S}^{l}-c_{S}+T^{+}\right)$,

see nodes \#1 and \#2 in Figure 5.

25 Eq.(13) can also be written as:

$b_{s}^{l}-c_{S}+(1-\gamma) T^{-}<\delta_{S}\left(T^{+}-T^{-}\right)$.

Non-cooperation in the first period hence becomes the more attractive for 1-types (a) 30 the higher $T^{+}$, the lower $T^{-}$and the higher $\delta_{S}$, as all three are directly related to the present value of the additional transfer $\left(T^{+}-T^{-}\right)$in the second stage, (b) the lower $b_{S}^{l}$, which lowers the opportunity costs of non-cooperation (i.e. foregone abatement) 
in the first stage, and (c) the higher $\gamma$ and $c_{S}$, for which higher values increase the incentive to behave non-cooperatively in the first stage. The first condition for a separating equilibrium requires that if South is a high-benefit type, she prefers cooperating and accepting the transfer $T^{-}$in both periods over the alternative of noncooperation in the first stage and cooperation with transfer $T^{+}$in the second stage:

$$
\left(b_{S}^{h}-c_{S}+T^{-}\right)+\delta_{S}\left(b_{S}^{h}-c_{S}+T^{-}\right)>\gamma T^{-}+\delta_{S}\left(b_{S}^{h}-c_{S}+T^{+}\right),
$$

see nodes \#3 and \#4 in Figure 5.

10

Eq.(14) can also be expressed as:

$$
b_{s}^{h}-c_{S}+(1-\gamma) T^{-}>\delta_{S}\left(T^{+}-T^{-}\right),
$$

15 Cooperating in the first period (thus truthfully revealing its type) becomes the more attractive for an h-type (a) the larger $T^{-}$, the lower $T^{+}$, and the lower $\delta_{S}$, which jointly determine the additional pay-off from the higher transfer $\left(T^{+}-T^{-}\right)$in the second stage, (b) the larger $b_{S}^{h}$, which increases the opportunity costs of noncooperation (i.e. foregone abatement) in the first stage, and (c) the lower $\gamma$ and $c_{S}$, as lower values of both parameters decrease the incentive to behave non-cooperatively in the first stage.

Again, a separating equilibrium only exists if both conditions (13) and (14) are fulfilled, requiring $b_{S}^{l}$ to be sufficiently small and $b_{S}^{h}$ sufficiently large. Otherwise, a 25 pooling equilibrium emerges. With the parameters of our numerical example, Eq.(13) implies $\delta_{S}<1.12$ and Eq.(14) $\delta_{S}>-0.067$. As $\delta_{S}$ is by definition non-negative, the condition for the existence of a separating equilibrium is $\delta_{S}<1.12$.

\section{$<<$ Figure 4 about here $>>$}




\section{The Model in Continuous Time}

Instead of assuming two separate stages, we now extend the model to analyze the signaling mechanism described in the preceding section, in continuous time. Accordingly, we focus on cases in which cooperation is impeded by asymmetric information as described in Section 3. Instead of assuming a discrete preliminary stage, the game proceeds in continuous time. We show how in such a setting the time during which early or delayed action is maintained can act as a signal of a player's

10 true type. That is, the. game becomes a game of timing in which players' pure strategies are stopping times $t_{C}{ }^{16}$.

We assume that the game has infinite length, that costs as well as benefits occur continuously throughout time, and that future costs and benefits are discounted at a uniform and constant rate $r$. The game's resolution mechanism then is the following: the country aiming to convey the signal has to uphold it for a time of at least $t_{C}$ in order to be credible. As for the game in discrete time, a separating equilibrium exists if pay-off maximizing regions of different types choose different strategies, i.e. selfselect such that they do not have an incentive to misrepresent their type.

Proposition 3: If cooperation is impeded by asymmetric information, maintaining early action for a time of at least $t_{C}$ in the game in continuous time can be a credible signal of high benefits for North

25 Proof: Signaling high benefits through early unilateral action is possible if there exists a $t_{C}$ such that (i) high-benefit types find it beneficial to incur the net costs of unilateral provision of the public good if they are rewarded with cooperation in the future, while (ii) for low-benefit types these costs exceed the benefits of cheating.

\footnotetext{
${ }^{16}$ see Fudenberg and Tirole (1991) for a discussion of games of timing
} 
North's first incentive compatibility condition hence requires that for h-types the net present value of the pay-offs of early action plus cooperation afterwards exceeds the pay-off from playing non-cooperatively over the entire time horizon:

$5 \quad \int_{0}^{t_{c}}\left(b_{N}^{h}-c_{N}\right) e^{-r t} d t+\int_{t_{c}}^{\infty}\left(b_{N}^{h}-T\right) e^{-r t} d t>0$.

Solving for $t_{c}$ results in:

$t_{C}<\ln \left(\frac{b_{N}^{h}-T}{c_{N}-b_{N}^{h}}\right) / r \equiv t_{C}^{\max }$.

10

Hence, $t_{C}$ is the larger (a) the greater $b_{N}^{h}$ and the smaller $T$ and $r$, which determine the present value of future cooperation, and (b) the smaller $c_{N}$, which determines the cost of sending the signal.

15 The second incentive compatibility condition requires that for l-types maintaining the signal until $t_{C}$ but then cheating on South's cooperation yields a lower payoff than playing non-cooperatively over the whole time period:

$$
\int_{0}^{t_{c}}\left(b_{N}^{l}-c_{N}\right) e^{-r t} d t+\int_{t_{c}}^{\infty} \gamma b_{N}^{l} e^{-r t} d t<0,
$$

which yields the following expression for $t_{C}$ :

$$
t_{C}>\ln \left(1+\frac{\gamma b_{N}^{l}}{c_{N}-b_{N}^{l}}\right) / r \equiv t_{C}^{\min } .
$$

$25 t_{C}$ gets the shorter (a) the smaller $\gamma$ and the larger $b_{N}^{l}$ and $r$, which are related to the rewards from free-riding after $t_{C}$, and (b) the larger $c_{N}$, on which the costs of the signal up to $t_{C}$ depend. 
The first condition identifies the maximum time over which an h-type would incur early action, and the second one the minimum time before it becomes unattractive for an 1-type to take early action to pass as an h-type. Hence, a separating equilibrium 5 exists if $t_{C}^{\min }<t_{C}^{\max }$, i.e. if:

$$
1+\frac{\gamma b_{N}^{l}}{c_{N}-b_{N}^{l}}<\frac{b_{N}^{h}-T}{c_{N}-b_{N}^{h}} .
$$

This is the more likely to hold (a) the larger $b_{N}^{h}$ and the lower $T$, which both determine the net benefits of cooperation, and (b) the lower $b_{N}^{l}$ and $\gamma$, on which the incentives to cheat depend ${ }^{17}$. This means that a separating equilibrium exists contingent of the choice of appropriate parameters.

Proposition 4: If cooperation is impeded by asymmetric information), playing noncooperatively for a time of at least $t_{C}$ in the game in continuous time can act as a credible signal of low benefits for South

Proof: Signaling low benefits through delayed cooperation is possible if there exists a $t_{C}$ such that (i) l-types find it more beneficial to play non-cooperatively until $t_{C}$ and 20 then be rewarded with cooperation and the higher transfer $T^{+}$later, while (ii) for a htype the pay-off of playing cooperatively from the beginning (and receiving the lower transfer $T^{-}$) is higher than what she would gain from misrepresenting her type.

The first condition for the existence of a separating equilibrium can therefore be 25 written as:

$$
\int_{0}^{t_{c}} \gamma T^{-} e^{-r t} d t+\int_{t_{c}}^{\infty}\left(b_{S}^{l}-c_{S}+T^{+}\right) e^{-r t} d t>\int_{0}^{\infty} \gamma T^{-} e^{-r t} d t .
$$

\footnotetext{
${ }^{17}$ Note that, although both incentive compatibility conditions inversely depend on $r$, the value of the discount rate exclusively influences the time until the game is resolved, but not the feasibility of a separating equilibrium
} 
As South's benefits of cooperation exceed the benefits of free-riding for all cases relevant for this proposition, the above condition is always satisfied. This can be explained by the fact that for an 1-type non-cooperation is the best response to North offering a benefit of $T^{-}$, such that she (unlike an h-type, for whom delaying action

5 implies opportunity costs) would rather choose non-cooperation for an infinite length of time than cooperate with a transfer of $T^{-}$. Hence, an 1-type only agrees to cooperate once North offers a transfer $T^{+}$.

Similarly, the second incentive compatibility condition can be expressed as:

10

$\int_{0}^{t_{c}} \gamma T^{-} e^{-r t} d t+\int_{t_{c}}^{\infty}\left(b_{S}^{h}-c_{S}+T^{+}\right) e^{-r t} d t<\int_{0}^{\infty}\left(b_{S}^{h}-c_{S}+T^{-}\right) e^{-r t} d t$

This results in the following expression for $t_{C}$ :

$15 t_{C}>\ln \left(1+\frac{T^{+}-T^{-}}{b_{S}^{h}-c_{S}+(1-\gamma) T^{-}}\right) / r \equiv t_{C}^{\min }$.

$t_{C}$ depends (a) positively on the difference between $T^{+}$and $T^{-}$(which is the reward for transmitting the signal, incurred from $t_{C}$ to infinity) and $\gamma$ (which influences the attractiveness of non-cooperation), and (b) negatively on the difference between $b_{S}^{l}$ and $c_{S}$ (i.e. the net benefit of providing the public good) and $r$ (which determines the present values of pay-offs occurring in the future).

Therefore, in continuous time, a separating equilibrium always exists; it requires a waiting time of at least $t_{C}^{\mathrm{min}}$ (Eq. 22) before the cooperative outcome emerges ${ }^{18}$.

\section{Conclusions}

\footnotetext{
${ }^{18}$ In this regard, the game bears resemblance to a 'war of attrition', in which the party that is willing to wait for the longest time eventually receives the reward (see Bliss and Nalebuff 1984)
} 
This paper has argued that uncertainty concerning other regions' benefits of mitigating climate change, which can be considered private information, might play an important role in the current stalemate to achieve a global climate agreement. We have shown that there are indeed constellations in which signaling - i.e. truthfully revealing private information - can be welfare improving for both players. Sections 4 and 5 identify situations in which cooperation is mutually desirable but can only arise after a period of signaling activity and highlight that for North early action and delaying action for South, can act as signals for high, respectively low, benefits. Therefore, it is conceivable that international cooperation on climate change might 10 arise in the future once all players' benefits have been credibly established. As it is the case for any credible signal, early action by some regions and delayed action by others involves social costs. For climate change, these costs can be expected to be substantial, as delaying global action renders the most ambitious climate targets impossible to achieve and severely increases the costs of meeting intermediate 15 stabilization targets.

The stylized model presented in this article suggests three conclusions that are directly relevant for policy: first, expectations about other regions' benefits from mitigating climate change are crucial for cooperation. Therefore, performing further research on regional climate change damages as well as achieving a shared understanding of these seems clearly mandated. Second, by setting up a system of monitoring and verification on a regular basis in short intervals, free-rider incentives can be reduced and cooperation be rendered more likely ${ }^{19}$. Third, applying appropriate incentive mechanisms derived from contract theory in international climate negotiations might

25 offer an opportunity to circumvent some of the most serious problems related to informational asymmetries. These arguments underline that even without a 'world government' that enables countries to enter binding arrangements, appropriately designed institutions can play a crucial role to achieve cooperation by creating regimes that provide information and influence expectations (cf. Keohane and Martin, 1995)

\footnotetext{
${ }^{19}$ Note that in the framework of our model, is the more likely to hold the smaller $\gamma$, i.e. the fraction of the payoff that can be appropriated with free-riding (cf. Eq.(4)).
} 
The research presented in this contribution could be extended in several directions: examining the case with more than two countries could provide valuable insights on more complex strategic interactions (e.g. incentives to free-ride on other regions' provision of a signal), as could the inclusions of additional signaling devices, such as $R \& D$, adaptation measures, or endogenous choice of abatement efforts and transfer payments. Another fruitful line of research might be the analysis of games in which all players are simultaneously confronted with uncertainty. Finally, we are convinced that examining the interplay of signaling motives with strategies to secure favorable bargaining positions in future negotiations à la Harstad (2009) and Beccherle and

10 Tirole (2010) would make a significant contribution to the field.

\section{References}

Barrett, S. (1994): Self-Enforcing International Environmental Agreements, Oxford Economic Papers, New Series, vol. 46, Special Issue on Environmental Economics, pp. 878-894

Batabyal, A.A. (2000): On the Design of International Environmental Agreements for Identical and Heterogeneous Developing Countries, Oxford Economic Papers, vol. 52(3), pp. 560-83

Beccherle, J. and Tirole, J. (2010): Regional Initiatives and the Cost of Delaying Binding Climate Change Agreements, mimeo

Bliss, C., Nalebuff, B. (1984): Dragon-slaying and ballroom dancing: The private supply of a public good, Journal of Public Economics, vol. 25(1-2), pp. 1-12

Brandt, U.S. (2004): Unilateral actions, the case of international environmental problems, Resource and Energy Economics, vol. 26(4), pp. 373-391

Caparrós A., Péreau J.-C. and Tazdaït, T. (2004): North-South Climate Change Negotiations: A Sequential Game with Asymmetric Information, Public Choice, vol. 121(3), pp. 455-480

Carbone, J., Helm, C., and Rutherford, T.F. (2009): The case for international emission trade in the absence of cooperative climate policy, Journal of Environmental Economics and Management, vol. 58(3), pp. 266-280 
Carraro, C., Eyckmans, J. and Finus, M. (2006): Optimal transfers and participation decisions in international environmental agreements, The Review of International Organizations, vol. 1(4), pp. 379-396

5 Carraro C. and D. Siniscalco (1993): Strategies for the International Protection of the Environment, Journal of Public Economics, vol. 52(3), pp. 309-328

Clarke, L., Edmonds, J., Krey, V., Richels, R., Rose, S., Tavoni, M. (2009): International climate policy architectures: Overview of the EMF 22 International Scenarios. Energy Economics, vol. 31, Supplement 2, pp. S64-S81.

Denicolò, V. (2008): A signaling model of environmental overcompliance, Journal of Economic Behavior \& Organization, 68(1), pp. 293-303

EC (2010): Analysis of options to move beyond 20\% greenhouse gas emission reductions and assessing the risk of carbon leakage, $\operatorname{COM(2010)~} 265$ final

Edmonds, J.; Clarke, L.; Lurz, J.; Wise, M. (2008): Stabilizing $\mathrm{CO}_{2}$ concentrations with incomplete international cooperation, Climate Policy, vol. 8, pp. 355-376

Finus, M. and Rübbelke, D.T.G. (2008): Coalition Formation and the Ancillary Benefits of Climate Policy, Stirling Economics Discussion Papers 2008-13, University of Stirling, Department of Economics.

25 Fudenberg, D., Tirole, J. (1991): Game Theory. The MIT Press

Gardiner S. M. (2004): Ethics and Global Climate Change. Ethics 114 (3), pp. 555598

30 Harstad, B. (2009): The Dynamics of Climate Agreements. Harvard Project on International Climate Agreements Discussion Paper 09-28

Harstad, B. and Eskeland, G.S. (2010): Trading for the Future: Signaling in Permit Markets, Journal of Public Economics, forthcoming

Helm, C. and Wirl, F. (2010): International Environmental Agreements: Incentive Contracts with Multilateral Externalities, mimeo

IPCC (2007): Climate Change 2007: Impacts, Adaptation and Vulnerability. Contribution of Working Group II to the Fourth Assessment Report of the Intergovernmental Panel on Climate Change, M.L. Parry, O.F. Canziani, J.P. Palutikof, P.J. van der Linden and C.E. Hanson, Eds., Cambridge: Cambridge University Press, UK

Jakob, M., G. Luderer, J. Steckel, M. Tavoni, S. Monjon (2011): Time to act now? Assessing the costs of delaying climate measures and benefits of early action. Submitted

Keohane, Robert O. and Lisa L. Martin (1995): The Promise of Institutionalist 
Kreps, D.M. (1990): A Course in Microeconomic Theory, Princeton Univ Press.

Laffont, J.J. and Martimort, D. (2005): The design of transnational public good mechanisms for developing countries, Journal of Public Economics, vol. 89(2-3), pp. 159-196

Mason, C. (2010): Carbon Sequestration Policy When Government Budgets Matter: Contracting Under Asymmetric Information, mimeo

Matsueda, N. (2004): Potential Failure of an International Environmental Agreement under Asymmetric Information, Economics Bulletin, vol. 17(4), pp. 1-8.

Pittel, K., and Rübbelke, D. T.G. (2008): Climate policy and ancillary benefits: A survey and integration into the modelling of international negotiations on climate change, Ecological Economics, vol. 68(1-2), pp. 210-220

Rose, A.K. and Spiegel, M.M. (2009): Noneconomic Engagement and International Exchange: The Case of Environmental Treaties, Journal of Money, Credit and Banking, vol. 41(2-3), pp. 337-363

Schelling, T. (1960): The Strategy of Conflict, Harvard University Press

Spence, M.A (1973): Job Market Signaling, The Quarterly Journal of Economics, vol. 87(3), pp. 355-74

Stern, N. (2007): The Economics of Climate Change. Cambridge University Press

Stiglitz, J.E. (2000): The Contributions of the Economics of Information to Twentieth Century Economics, The Quarterly Journal of Economics, vol. 115 (4), pp. 14411478

van Vliet J., den Elzen M.G.J., van Vuuren D.P. (2009): Meeting radiative forcing targets under delayed participation. Energy Economics, vol. 31, pp. 152-162

Weikard, H.P. Finus, M., and Altamirano-Cabrera, J.C. (2006): The impact of surplus sharing on the stability of international climate agreements, Oxford Economic Papers, vol. 58, pp. 209-232 


\section{Figures}

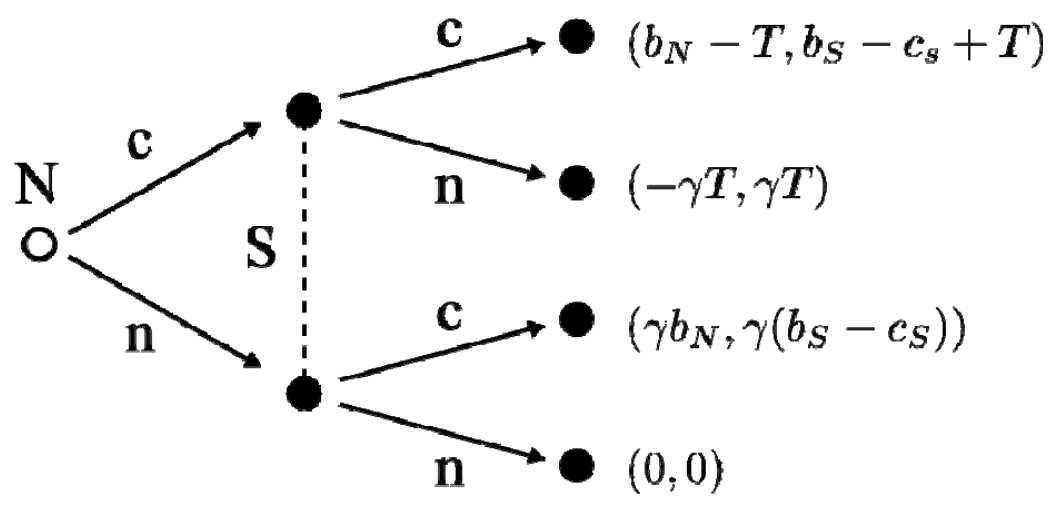

Figure 1: The IEA game with complete information in extended form ${ }^{20}$

${ }^{20}$ The graphical elements in our extended form games are borrowed from Kreps (1990), in particular dashed lines connect decision nodes that belong to the same information set. 


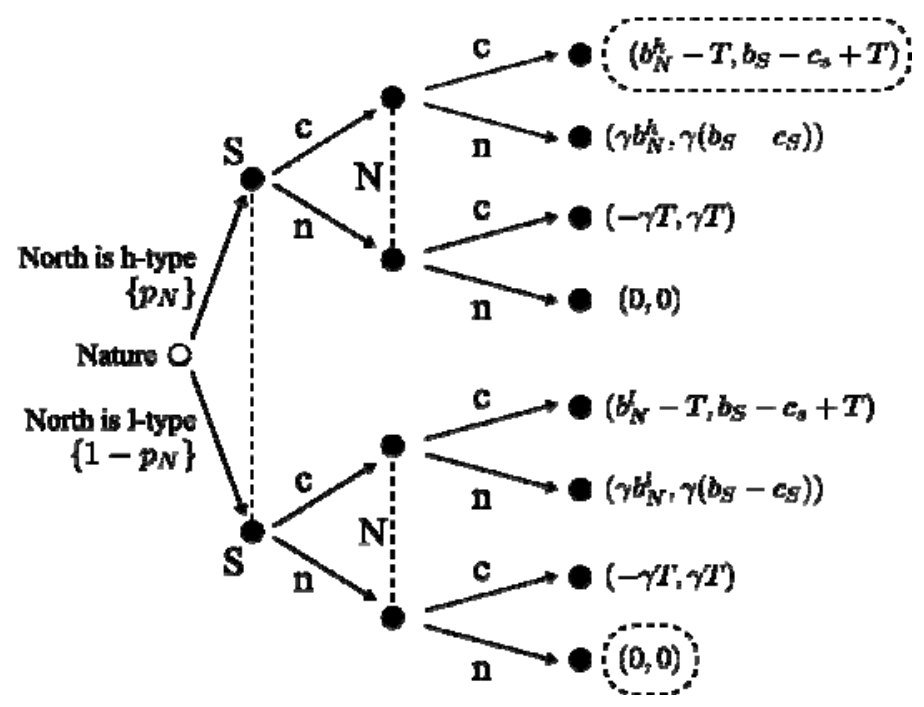

Figure 2: The IEA Game with Uncertainty about North's Benefits in Extended Form. Dashed ellipses denote the Nash-equilibria of the respective sub-game for the case that North's action depends on his type (i.e. Eq.(4') holds) 


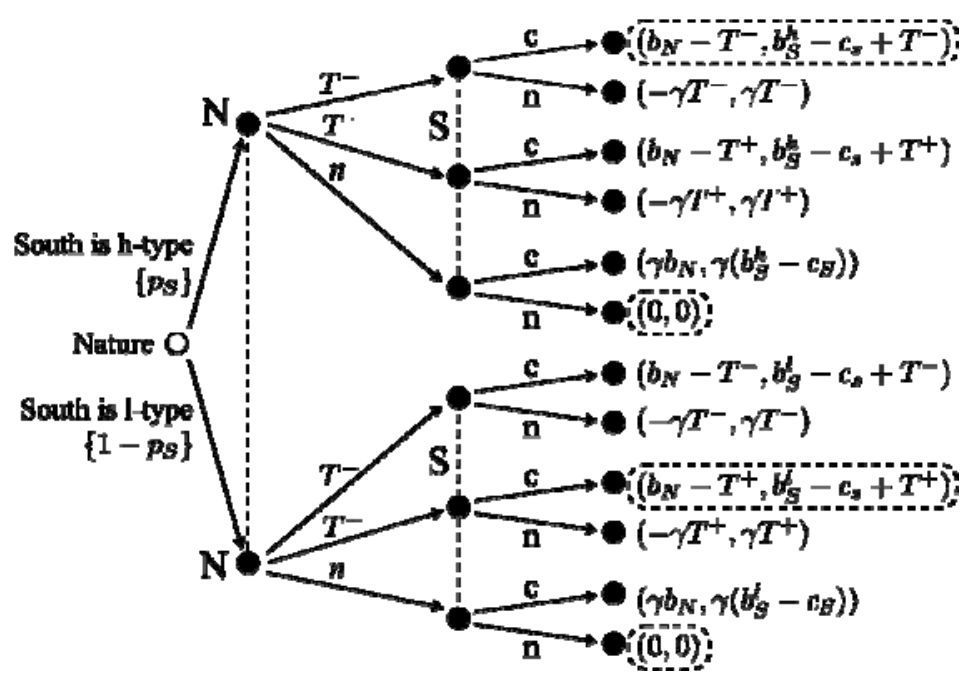

Figure 3: The IEA Game with Uncertainty about South's benefits in Extended Form. Dashed ellipses denote the Nash-equilibria of the respective sub-game for the case that South's reaction to the transfer offered by North depends on her type (i.e. Eq.(1') holds) 


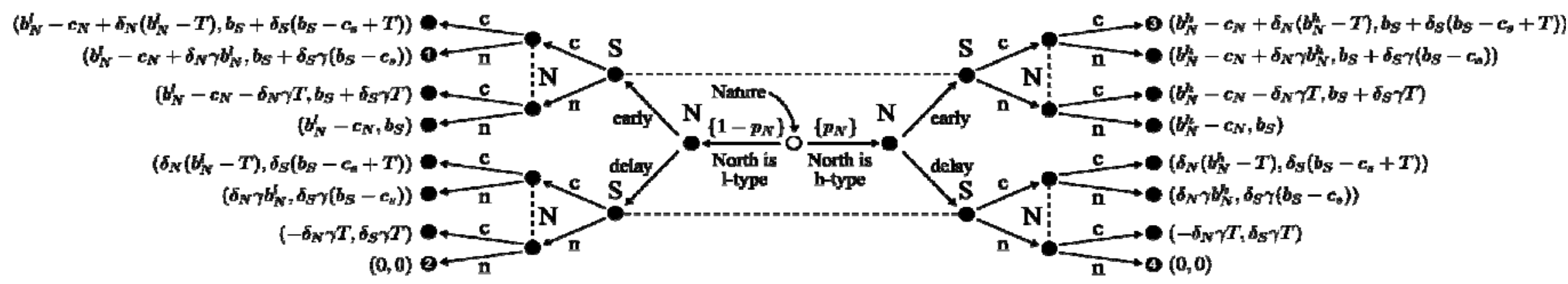

Figure 4: The Two-Stage Signaling Game if North's Type is Uncertain in Extended Form 


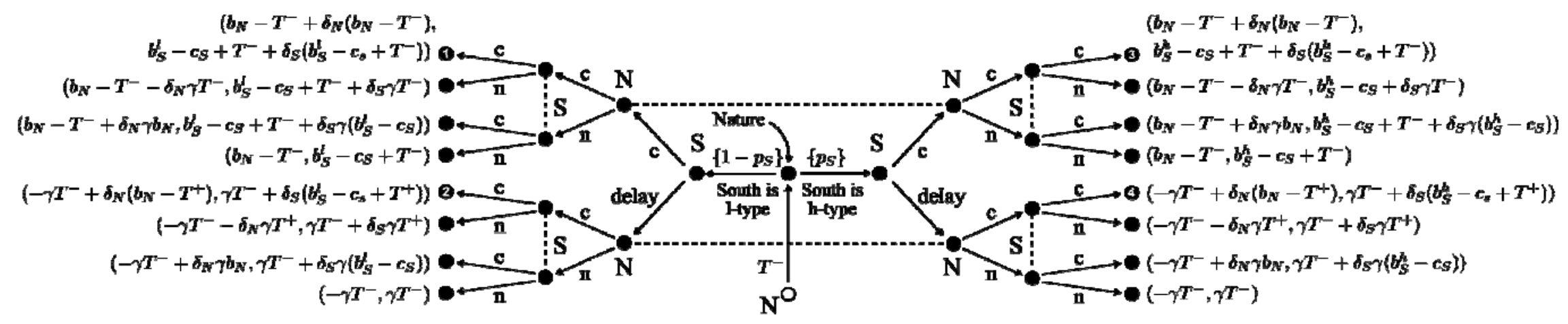

Figure 5: The Two-Stage Signaling Game if South's Type is Uncertain in Extended Form 


\section{Tables}

\begin{tabular}{|l|l|l|l|l|}
\hline \multicolumn{3}{|c|}{ Parameters } & Transfers & Probabilities \\
\hline$b_{N}^{h}=6 \%$ & $b_{S}^{h}=2 \%$ & $\alpha=2 / 3$ & $T^{+}=3.27 \%$ & $p_{N}>0.39$ \\
\hline$b_{N}^{l}=3 \%$ & $b_{S}^{l}=1 \%$ & $\gamma=0.2$ & $T^{-}=2.43 \%$ & $p_{S}<0.79$ \\
\hline$c_{N}>6 \%$ & $c_{S}=3 \%$ & & & \\
\hline
\end{tabular}

Table 1: Parameters and results of the numerical example.

Costs and benefits are $\%$ of global GDP, $p_{\mathrm{N}}$ and $\mathrm{p}_{\mathrm{s}}$ are probabilities required for cooperation 